\title{
Intraoperative use of methadone improves control of postoperative pain in morbidly obese patients: a randomized controlled study
}

This article was published in the following Dove Press journal: Journal of Pain Research

\author{
Felipe Chiodini Machado \\ Claudia Carneiro de Araújo \\ Palmeira \\ João Nathanael Lima Torres \\ Joaquim Edson Vieira \\ Hazem Adel Ashmawi
}

Anesthesiology Department, hcFMUsP, Universidade de São Paulo, São Paulo, Brazil

Correspondence: Felipe Chiodini Machado

Universidade de São Paulo, HCFMUSP, Anesthesiology Department, Rua Oscar Freire, 2040, ap. 56, São Paulo 05409-0 I I, Brazil

Tel +55 II 1999432343

Fax +55 II2 66I 7947

Email felipe.chiodini@hotmail.com
Objectives: Surgical patients still commonly experience postoperative pain. With the increasing prevalence of obesity, there is a growing demand for surgical procedures by this population. Intraoperative use of methadone has not been well assessed in this population.

Materials and methods: Patients with a body mass index of $35 \mathrm{~kg} / \mathrm{m}^{2}$ or more undergoing bariatric surgery were randomly assigned to receive either fentanyl (group F) or methadone (group $\mathrm{M})$ in anesthesia induction and maintenance. The primary outcome was morphine consumption during the first 24 hours after surgery through a patient-controlled analgesia device. Secondary outcomes were pain scores at rest and while coughing, opioid related side effects, and patient satisfaction. The patients were also evaluated 3 months after surgery for the presence of pain, dysesthesia, or paresthesia at surgical site.

Results: Postoperative morphine consumption was significantly higher for patients receiving fentanyl than methadone during the postoperative period at 2 hours (mean difference [MD] 6.4 mg; 95\% CI 3.1-9.6; $P<0.001$ ), 2-6 hours (MD 11.4 mg; 95\% CI 6.5-16.2; $P<0.001$ ), 6-24 hours (MD $10.4 \mathrm{mg} ; 95 \%$ CI 5.0-15.7; $P<0.001$ ), and 24-48 hours (MD $14.5 \mathrm{mg}$; 95\% CI $3.9-25.1 ; P=0.01)$. Patients from group $\mathrm{F}$ had higher pain scores until 24 hours postoperatively, higher incidence of nausea and vomiting, lower satisfaction, and more evoked pain at surgical scar at the 3-month postoperative evaluation than group $\mathrm{M}$.

Conclusion: Intraoperative methadone can safely lower postoperative opioid consumption and improve postoperative pain scores compared with fentanyl in morbidly obese patients.

Keywords: postoperative pain, bariatric surgery, acute pain, postoperative pain, methadone

\section{Introduction}

Despite recent developments in postoperative pain management, many patients still suffer from moderate-to-severe pain after surgery. It is estimated that postoperative severe pain occurs in $20 \%-40 \%$ of all surgical procedures. ${ }^{1}$ Pain during the first days after surgery might lead to severe complications, such as delayed ambulation, increased incidence of cardiovascular and pulmonary complications with increased morbidity and mortality, and the development of chronic postoperative pain. ${ }^{1-6}$ Therefore, the proper treatment of postoperative pain is of great importance, especially in procedures that lead to severe pain.

The prevalence of morbid obesity is increasing in most countries, and there is a growing demand for surgical procedures in these patients (both related and not related to obesity). The postoperative pain management in these patients is especially important, considering this population has greater susceptibility to cardiovascular, pulmonary, and thromboembolic complications in the perioperative period..$^{7-9}$ 
Methadone is a strong $\mu$-opioid receptor (MOR) agonist. It antagonizes glutamate by blocking the $N$-methyl-D-aspartate receptor (NMDAr) and inhibits the reuptake of serotonin and noradrenaline in the central nervous system. When used parenteral, its latency is of 10-20 minutes, with 4-36 hours of action, depending on the dosage, due to its long half-life and the large individual variation. ${ }^{10,11}$ When administered in doses of 20-30 mg, analgesia generated by intravenous (i.v.) methadone can last from 24 to 36 hours. $^{12}$

Methadone may be an interesting option in the treatment of postoperative pain, and the dose used in anesthesia may contribute to immediate postoperative analgesia, when the highest pain scores are usually reported. Few published studies have compared intraoperative methadone to fentanyl or sufentanil in cardiac surgery, ${ }^{13,14}$ spine surgery, ${ }^{15}$ laparoscopy, ${ }^{16}$ hysterectomy, ${ }^{17,18}$ abdominal surgery, ${ }^{18,19}$ and major surgery in children. ${ }^{20}$ To our knowledge, no study has compared the use of intraoperative methadone with other opioids for the morbidly obese patients.

The present study was designed to evaluate the efficacy and safety of intraoperative i.v. methadone in reducing postoperative pain and opioid consumption in morbidly obese patients submitted to open bariatric surgery.

\section{Materials and methods}

This study was approved by the University of São Paulo Institutional Review Board (identifier 1.412.317) and written informed consent was obtained from all subjects participating in the trial. The trial was registered prior to patient enrollment at ClinicalTrials.gov (NCT02775474, principal investigator: FCM, date of registration: May 17, 2016).

Subjects included were submitted to open bariatric surgery (with or without Roux-en-Y anastomosis) performed by the same team of surgeons and anesthetists. The inclusion criteria were American Society of Anesthesiologists II patients, aged 18-65 years scheduled for bariatric surgery. The exclusion criteria were refusal by the patient, cardiac or coronary disease, cardiac conduction abnormalities (QT interval duration of $450 \mathrm{~ms}$ or more), creatinine clearance lower than $60 \mathrm{~mL} / \mathrm{min}$, psychiatric mood or personality disorders, use of preoperative opioids or history of opioid misuse, and allergy to any of the study used drugs. Patients were allocated into two groups using computer-generated randomization, and demographic data were obtained. This manuscript adhered to the applicable Consolidated Standards of Reporting Trials guidelines.

A nonblind medical assistant prepared the induction syringe and the opioid bolus solution for each patient. This assistant did not participate in any other part of data collection and patient information and allocation were kept in opaque sealed envelopes. All other assistants and health professionals involved were blinded, including preoperative, intraoperative and postoperative assessments. The induction syringe contained either methadone $0.15 \mathrm{mg} / \mathrm{kg}$ (group M) or fentanyl $6 \mu \mathrm{g} / \mathrm{kg}$ (group F), and each $5 \mathrm{~mL}$ bolus of the opioid bolus solution contained either methadone $0.05 \mathrm{mg} / \mathrm{kg}$ or fentany $12 \mu \mathrm{g} / \mathrm{kg}$. These doses have been demonstrated to be approximately equipotent ${ }^{21-23}$ and were diluted in a standardized format so that the final presentation was identical for both groups. The weight used to calculate the dosages was the ideal body weight (IBW) plus $20 \%$ calculated by Robinson's formula, ${ }^{24}$ which is the most precise equation currently available to determine IBW. ${ }^{25}$

Anesthesia was induced with i.v. midazolam (3 mg), propofol titrated until loss of consciousness, and cisatracurium $(0.15 \mathrm{mg} / \mathrm{kg}$ total body weight). At induction, the patients received either methadone $(0.15 \mathrm{mg} / \mathrm{kg} \mathrm{IBW}+20 \%)$ or fentanyl $(6 \mu \mathrm{g} / \mathrm{kg}$ IBW+20\%). Maintenance of anesthesia consisted of sevoflurane $1.8 \%-2.2 \%$ and repeated boluses of cisatracurium for optimal surgical relaxation. Hypotension (decrease of $20 \%$ or more in initial blood pressure) was treated with boluses of metaraminol $(0.5 \mathrm{mg})$ or ephedrine ( $5 \mathrm{mg}$ ) as clinically indicated. Hypertension (any value higher than initial blood pressure) was treated with boluses from the same induction opioid: either methadone $(0.05 \mathrm{mg} /$ $\mathrm{kg} \mathrm{IBW}+20 \%)$ or fentanyl $(2 \mu \mathrm{g} / \mathrm{kg}$ IBW $+20 \%)$ every 10 minutes if necessary. The opioid dilution was calculated so the anesthesiologist would always administer $5 \mathrm{~mL}$ of the opioid bolus solution if needed. Monitoring consisted of a five-lead electrocardiogram, pulse oximetry, noninvasive pressure monitoring, esophageal temperature, capnography, and gas analyzer. Adjuvants were used for an optimal multimodal analgesia and prevention of postoperative nausea and vomiting (PONV) at the beginning of the procedure (pantoprazole $40 \mathrm{mg}$, dexamethasone $4 \mathrm{mg}$, and ketoprofen $100 \mathrm{mg}$ ) and at its end (dipyrone $2 \mathrm{~g}$, ondansetron $4 \mathrm{mg}$, and morphine $3 \mathrm{mg}$ ). A median upper abdominal incision was performed in all subjects, and all incisions were infiltrated with $20 \mathrm{~mL}$ of $0.375 \%$ ropivacaine by the surgeon. Prior to extubation, all patients received neostigmine $30 \mu \mathrm{g} / \mathrm{kg}$ and atropine $15 \mu \mathrm{g} / \mathrm{kg}$. After extubation, if hypoventilation (respiratory rate less than 8) refractory to continuous positive airway pressure for 15 minutes occurred, naloxone 40 $\mu \mathrm{g}$ was administered.

All patients used patient-controlled analgesia (PCA) (Hospira, Gemstar 7 Therapy $^{\circledR}$ ) for postoperative analgesia, installed in the operating room before transport to postanesthesia care unit (PACU). All PCA devices contained a $0.1 \%$ i.v. morphine solution, with a bolus of $2 \mathrm{mg}$, lockout interval 
of 5 minutes, and a 4 hour bolus limit of $30 \mathrm{mg}$. In addition, all patients received i.v. dipyrone $2 \mathrm{~g}$ every 6 hours.

In PACU, patients were monitored with electrocardiogram, pulse oximetry, and noninvasive pressure monitoring; patients remained in PACU for 2 hours before discharged to the ward.

Patients were assessed for pain using the visual analog pain score (VAS based on a $0-10$ scale; $0=$ no pain and $10=$ worst pain possible) and side effects 10 minutes after extubation. The Richmond Agitation -Sedation Scale (RASS) was used to evaluate sedation, and the anesthesia awakening time was recorded. If the patient was complaining of pain, he or she was reminded that the PCA device was available for use. The PCA device was available for 48 hours after surgery. After 48 hours, boluses of morphine were prescribed as needed.

The primary outcome was postoperative morphine consumption at 2, 6, 24, 48, and 72 hours after surgery. Secondary outcomes were pain score (VAS) at rest and while coughing, opioid-related side effects (nausea, vomiting, pruritus, urinary retention, and the necessity for supplementary oxygen), and sedation score (RASS) at 10 minutes after extubation and at 2, 6, 24, 48, and 72 hours postoperatively. Patient satisfaction with postoperative pain management was accessed at 24, 48, and 72 hours after surgery using a scale of $0=$ unsatisfied to $10=$ completely satisfied. Patients were also evaluated 3 months after surgery for the presence of spontaneous or evoked pain and the presence of dysesthesia or paresthesia in the incision area. Evoked pain was evaluated by manual palpation in and around the scar by the researcher. All care providers and research team members responsible for data collection were blinded to group assignment throughout the perioperative period.

We used the primary outcome measure to estimate the sample size. The average morphine consumption for this procedure observed from 20 previous patient's data was $28 \mathrm{mg}$ in the first 24 hours after surgery. Following other study results, we estimated that a $40 \%$ reduction in morphine consumption would be considered as clinically meaningful. Fifty-six patients were needed to detect the $40 \%$ difference in the postoperative morphine consumption between the groups, with a SD of $6 \%$, a test power of $80 \%$, and level of significance of $5 \%$.

\section{Statistical analysis}

Means were compared using the Student's $t$-test for normally distributed data, and medians were compared with Kruskal-Wallis test if the data were not normally distributed. Fisher's exact test was used to compare proportions. Two-way repeated-measures ANOVA was conducted with post hoc
Bonferroni correction. Statistical tests were two-sided and performed at a significance level of 0.05 .

\section{Results}

A total of 56 patients were scheduled to be included in the study. However, during the study, two clear different patterns of morphine consumption among patients were observed, with some patients consuming very low dosages of morphine while others consuming large amounts of morphine, and a preliminary analysis was performed by a nonblinded researcher. This analysis showed statistically relevant results and the recruitment stopped since one method of anesthesia was superior to the other, and patients that received fentanyl, group F, were using avoidable high doses of morphine. As a result, the analysis considered a total of 32 patients enrolled in the study, 16 in each group (Figure 1). Both groups were similar regarding demographic and clinical characteristics (Table 1). During anesthesia, both groups had similar intraoperative requirements regarding the opioid boluses needed, propofol dose at induction, the number of vasopressor boluses needed, intraoperative hydration, duration of anesthesia, and awakening time.

As for the primary outcome, group $\mathrm{F}$ postoperative mean morphine consumption was $6.5 \mathrm{mg}(95 \% \mathrm{CI} 3.2-9.7)$ at 2 hours, $12.5 \mathrm{mg}(95 \% \mathrm{CI} 7.4-17.1)$ at 2-6 hours, $13.5 \mathrm{mg}$ (95\% CI 8.3-18.7) at 6-24 hours, $16.6 \mathrm{mg}$ (95\% CI 6.1-27.2) at $24-48$ hours, and $4.2(95 \% \mathrm{CI}-0.3$ to 8.6$)$ at $48-72$ hours. Group M postoperative mean morphine consumption was 0.1 $\mathrm{mg}(95 \% \mathrm{CI}-0.1$ to 0.4$)$ at 2 hours, $0.9 \mathrm{mg}(95 \% \mathrm{CI} 0.2-1.6)$ at 2-6 hours, $3.1 \mathrm{mg}(95 \% \mathrm{CI} 1.9-4.4)$ at 6-24 hours, 2.1 $\mathrm{mg}(95 \% \mathrm{CI} 0.8-3.4)$ at $24-48$ hours, and 0.2 (95\% CI -0.1 to 0.6 ) at $48-72$ hours.

When comparing both groups, the postoperative morphine consumption was significantly higher in group $\mathrm{F}$ than group $\mathrm{M}$ until 48 hours and at the moments or intervals of 2 hours (mean difference [MD] $6.4 \mathrm{mg}$; 95\% CI $3.1-9.6 ; P<0.001$ ), 2-6 hours (MD $11.4 \mathrm{mg} ; 95 \% \mathrm{CI}$ 6.5-16.2; $P<0.001$ ), 6-24 hours (MD $10.4 \mathrm{mg} ; 95 \%$ CI $5.0-15.7 ; P<0.001$ ), and 24-48 hours (MD $14.5 \mathrm{mg} ; 95 \%$ CI $3.9-25.1 ; P=0.01)$. There was no difference in the opioid requirement in the 72-hour evaluation (MD $3.9 \mathrm{mg}$; $95 \% \mathrm{CI}$ -0.5 to $8.4 ; P=0.08$ ) (Figure 2 ).

Pain scores at rest were higher in group F at 2 hours (MD 3.1; 95\% CI 1.9-3.2; $P<0.001$ ), 6 hours (MD 2.4; 95\% CI $1.5-3.3 ; P<0.001$ ), and 24 hours (MD 0.9; 95\% CI 0.2-1.5; $P=0.001)$ than group $\mathrm{M}$. There was no statistical difference between the groups in the 48 hours (MD 0.2; 95\% CI -0.1 to $0.6 ; P=0.13$ ) and 72 hours (MD $0.1 ; 95 \% \mathrm{CI}-0.1$ to 0.4 ; $P=0.3$ ) postoperative scores. Pain scores at coughing were 


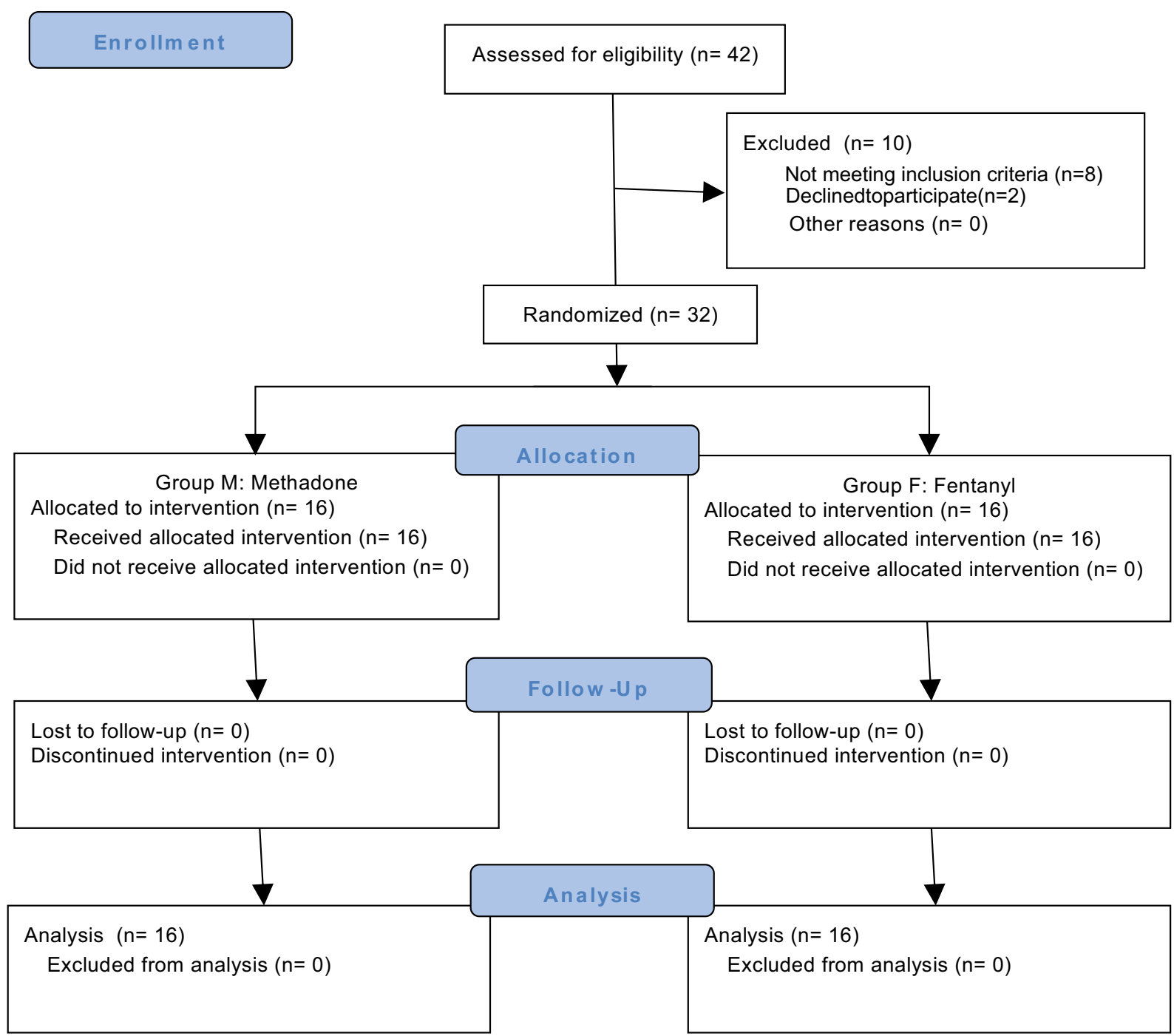

Figure I CONSORT flow diagram.

Abbreviation: CONSORT, Consolidated Standards of Reporting Trials.

higher in group $\mathrm{F}$ at 2 hours (MD 5.3; 95\% CI 4.1-6.5; $P<0.001$ ), 6 hours (MD 3.4; 95\% CI 2.4-4.5; $P<0.001$ ), 24 hours (MD 2.6; 95\% CI 1.3-3.9; $P<0.001$ ), and 72 hours (MD 1.2; 95\% CI 0.3-2.2; $P=0.02$ ), and no difference was observed at 48 hours between the two groups (MD 1.1; $95 \%$ CI -0.1 to $2.2 ; P=0.05$ ) (Figure 3).

Ten minutes after extubation, RASS score was similar in both groups, but group F patients had higher pain scores (VAS: mean 1.37; range 0-7) than group M patients (VAS: 0 for all patients at this evaluation; $P<0.01$; Kruskal-Wallis test). PONV was more common in group $\mathrm{F}$ than in group $\mathrm{M}$ at 10 -minutes evaluation ( $37.5 \%$ vs $0 \% ; P=0.02$; Fisher's exact test). The perioperative results are shown in Table 2. Opioid antagonist use was necessary in one patient of each group.

Opioid-related side effects occurred more frequently in group $\mathrm{F}$ than in group $\mathrm{M}$ for nausea $(75 \%$ vs $6.3 \% ; P=0.001$; Fisher's exact test) and vomiting $(31.3 \%$ vs $0 \% ; P=0.001$;
Fisher's exact test). The incidence of pruritus, need for supplementary oxygen, and RASS sedation scores were similar between the groups (Table 3). No patient had urinary retention; all patients scored 0 at RASS score at 24-, 48-, and 72-hour postoperative evaluations. No patients presented score higher than zero or lower than -2 at any of the postoperative evaluations. Also, no patient required supplementary oxygen for more than 6 hours postoperatively.

The median patient satisfaction score was also lower for group $\mathrm{F}$ compared with group $\mathrm{M}$ at 24 hours (8.5, range 6-10 vs 10 , range $9-10 ; P=0.004$; Kruskal-Wallis test), 48 hours (9.0, range $6-10$ vs 10 , range $9-10 ; P=0.015$; Kruskal-Wallis test), and 72 hours (9.5, range $7-10$ vs 10 , range $9-10$; $P=0.015$; Kruskal-Wallis test) postoperatively.

At the 3-month postoperative evaluation, both groups had similar pain at rest $(P=0.6$; Fisher's exact test), pain while coughing ( $P=0.39$; Fisher's exact test), and dysesthesia 
Table I Patient characteristics

\begin{tabular}{lll}
\hline Characteristic & Group F & Group M \\
\hline $\mathrm{N}$ & 16 & 16 \\
Sex (female) & $13(81.2 \%)$ & $1 \mathrm{I}(68.7 \%)$ \\
Age (years) & $43.2 \pm 11.0$ & $46.2 \pm 13.3$ \\
Body mass index $\left(\mathrm{kg} / \mathrm{m}^{2}\right)$ & $44.2 \pm 9.4$ & $47.6 \pm 5.7$ \\
ASA physical status & $2(100 \%)$ & $2(100 \%)$ \\
Smoking history & $5(31.2 \%)$ & $7(43.7) \%$ \\
Drinking history & 0 & 0 \\
Hypertension & $10(62.5 \%)$ & $12(75 \%)$ \\
Resistant hypertension & $\mathrm{a}$ & $5(31.2 \%)$ \\
IDDM & $5(31.2 \%)$ & $1(6.2 \%)$ \\
NIDDM & $2(12.5 \%)$ & $6(37.5 \%)$ \\
Thyroid disease & $6(37.5 \%)$ & $2(12.5 \%)$ \\
Dyslipidemia & $4(25 \%)$ & $6(37.5 \%)$ \\
Sleep apnea & $5(31.2 \%)$ & $3(18.7 \%)$ \\
Chronic musculoskeletal pain ${ }^{\mathrm{b}}$ & $2(12.5 \%)$ & $5(31.2 \%)$ \\
APFEL score & $6(37.5 \%)$ & $2.3(2-3)$ \\
\hline
\end{tabular}

Notes: Data are mean \pm SD (normal distribution), median [min - max] (non-normal distribution), or number of patients (\%). ${ }^{\text {Hypertension that remains uncontrolled }}$ (140/90 $\mathrm{mmHg}$ or higher) despite an optimal two-drug regimen that has had adequate time to work (at least I month since last drug or dosage adjustment). 'Pain for more than 3 months. Reported sites of pain were knees ( $18 \%$ of $n=32)$, lumbar ( $15 \%$ of $n=32$ ), and hip ( $9 \%$ of $n=32$ ). Drinking history= alcohol consumption of more than two drinks per day.

Abbreviations: ASA, American Society of Anesthesiologists; IDDM, insulindependent diabetes mellitus; NIDDM, non-insulin-dependent diabetes mellitus.

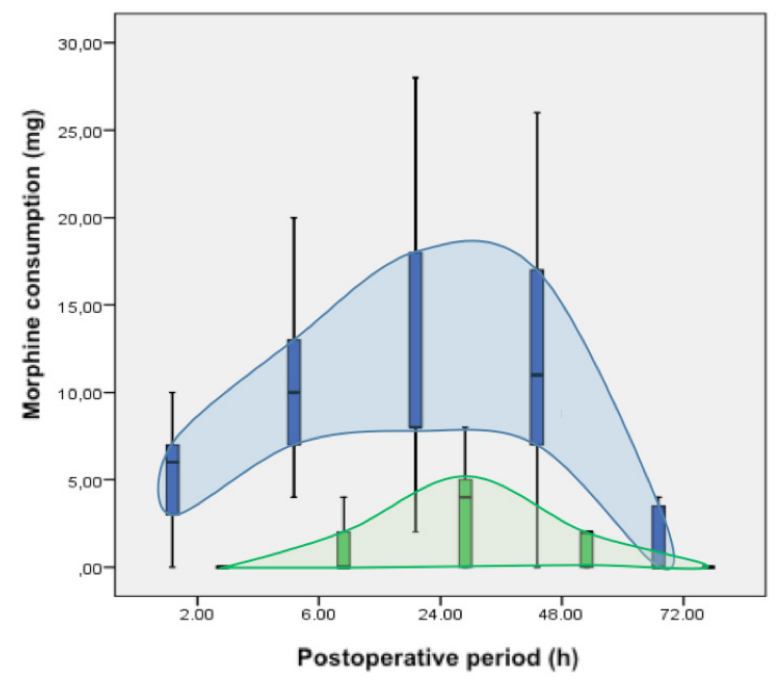

Figure 2 Postoperative morphine consumption $(\mathrm{mg})$.

Note: Data are mean (horizontal black straight segment), SD (boxplot: blue or green), and min and max (vertical black straight segment).

symptoms ( $P=1.0$; Fisher's exact test). However, group $\mathrm{F}$ had more evoked pain at surgical scar palpation ( $56 \%$ vs $12.5 \%$; $P=0.02$; Fisher's exact test) than group $\mathrm{M}$.

\section{Discussion}

Methadone in bariatric surgery showed to be safe and significantly reduced the postoperative opioid consumption, pain scores at rest and at movement, less opioid-related nausea and vomiting, and better patient satisfaction. Intraoperative methadone usage is relatively new in anesthesia and has not yet been extensively studied. This is the first trial to analyze intraoperative methadone use and postoperative pain management of morbidly obese patients.

Our primary outcome was postoperative morphine consumption. Patients receiving fentanyl had a higher need for opioid usage in the postoperative period until 48 hours. This result was greater than the initially proposed $40 \%$ difference in morphine consumption. These findings are consistent with other trials studying methadone as the sole opioid in anesthesia for nonobese patients. ${ }^{13,15,17}$ Secondary outcomes as pain at rest and while coughing were higher in group F right after extubation and 24 hours after surgery. Lower postoperative pain scores for methadone use are also in accordance with other studies conducted in nonobese patients. ${ }^{13,15,17}$

Patients receiving fentanyl experienced more opioidrelated side effects right after extubation and in the postoperative period until 72 hours. Patients on methadone presented less PONV. The incidences of pruritus, sedation, need for supplementary oxygen, and urinary retention were similar between groups. Patients were monitored with ECG for 2 hours at PACU, and no QT interval alterations were observed in both groups. Side effects with different opioids is still controversial in literature with some studies showing no difference in opioid-related side effects when comparing methadone with other opioids ${ }^{13,15,17,18}$ and one study that reported less of such side effects in the group that used methadone. ${ }^{14}$

Satisfaction with the postoperative pain management was higher among patients under methadone compared with those receiving fentanyl. We believe this is a consequence of the better analgesia provided by methadone, although the use of PCA is usually related to high scores of patient satisfaction since it easily alleviates pain when used. One study compared patient satisfaction with methadone versus fentanyl for cardiac surgery and found similar results. ${ }^{13}$

All patients in this study were submitted to the same protocol of general anesthesia and the same bariatric surgery technique. Intraoperative variables such as opioid, propofol and vasopressor boluses requirement, intraoperative hydration, duration of anesthesia, and awakening time were similar in both groups.

The methadone favorable outcomes in postoperative opioid consumption and pain scores could be the result of a combination of factors. Methadone has a longer elimination half-life (13-50 hours) ${ }^{10,12,19}$ than fentanyl (8-10 hours), ${ }^{26}$ which may lead methadone to maintain an analgesic effect longer than fentanyl. In addition, fentanyl has an analgesic 

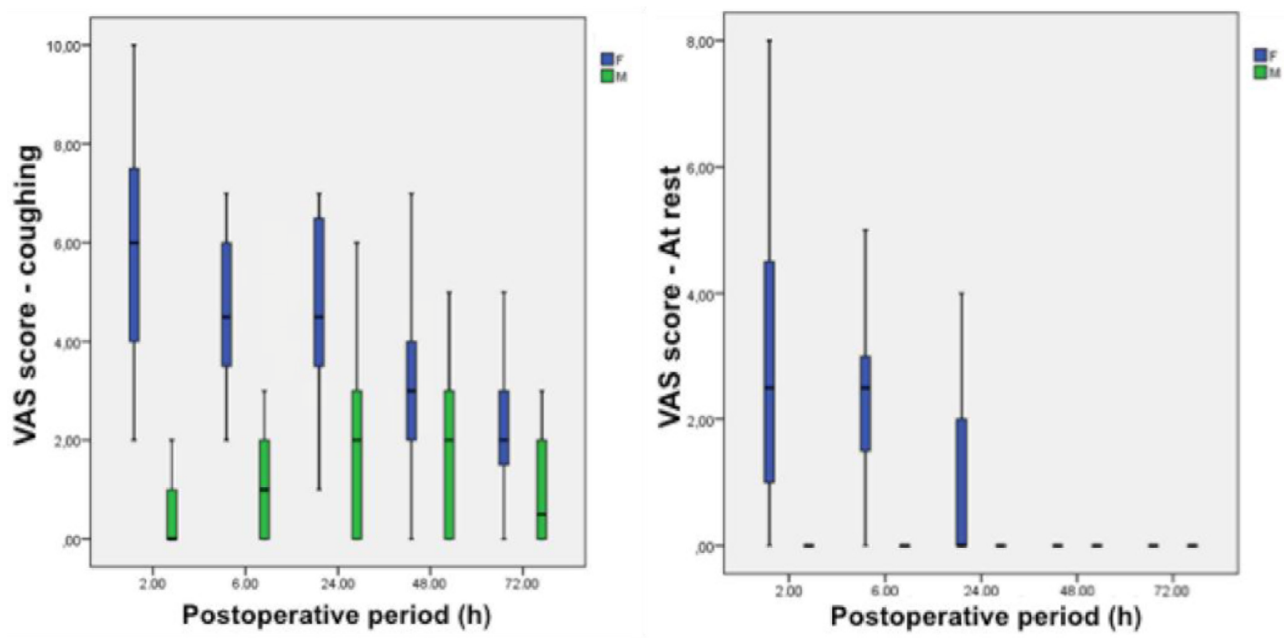

Figure 3 Postoperative pain scores.

Notes: (A) Pain scores while coughing. (B) Pain scores at rest. Data are mean (horizontal black straight segment), SD (boxplot: blue or green), and min and max (vertical black straight segment). When no patient reported pain (VAS=0), only a small horizontal line is presented.

Abbreviation: VAS, visual analog pain score.

Table 2 Perioperative period: intraoperative and 10 minutes after extubation

\begin{tabular}{llll}
\hline Perioperative evaluations & Group F $(\mathbf{n}=\mathbf{1 6})$ & Group M $(\mathbf{n}=\mathbf{1 6})$ & $\mathbf{P}$-value \\
\hline Propofol requirement at induction $(\mathrm{mg})$ & $130 \pm 39.8$ & $141.9 \pm 54.7$ & 0.49 \\
Volume of opioid boluses needed $(\mathrm{mL})^{\mathrm{a}}$ & $25.3 \pm 7.2$ & $21.6 \pm 6.8$ & 0.14 \\
Vasopressor bolus requirement $(\mathrm{n})^{\mathrm{b}}$ & $2[0-12]$ & $0.5[0-10]$ & 0.16 \\
Intraoperative crystalloids $(\mathrm{mL})$ & $1900 \pm 468.7$ & $1887 \pm 332.4$ & 0.93 \\
Length of anesthesia (minutes) & $250.0[220-310]$ & $250.0[220-300]$ & 0.73 \\
Awakening time (minutes) & $16.4 \pm 3.0$ & $16.8 \pm 4.1$ & 0.77 \\
RASS I0 minutes after extubation $(-5$ to +4$)$ & $-1.0[-4$ to 0] & $-1.1[-3$ to 0$]$ & 0.23 \\
Pain score I0 minutes after extubation $(0-10)$ & $0[0-7]$ & $0[0-0]$ & $<0.01$ \\
Nausea I0 minutes after extubation $(\mathrm{n})$ & $6(37.5 \%)$ & 0 & 0.02 \\
\hline
\end{tabular}

Notes: Variables with normal distribution are shown in each group as "mean \pm SD" and "P-value" calculated with Student's $t$-test. Variables with non-normal distribution are shown as "median [min-max]" and "P-value" calculated with Kruskal-Wallis test. Proportions are shown in each group as " $n$ (\%)" and " $P$-value" calculated with Fisher's exact test. "Milliliters of a standardized opioid solution used for identical final aspect in both groups. 'Standardized bolus of metaraminol or ephedrine.

Abbreviation: RASS, Richmond Agitation -Sedation Scale.

Table 3 Postoperative opioid-related side effects $-\mathrm{n}(\%)$

\begin{tabular}{|c|c|c|c|}
\hline Side effects & $\begin{array}{l}\text { Group F } \\
(n=16)\end{array}$ & $\begin{array}{l}\text { Group M } \\
(n=16)\end{array}$ & $P$-value ${ }^{a}$ \\
\hline Nausea & $12(75 \%)$ & $\mathrm{I}(6.25 \%)$ & 0.001 \\
\hline Vomiting & $5(3 \mid .25)$ & 0 & 0.001 \\
\hline Pruritus & $4(25 \%)$ & 0 & 0.10 \\
\hline Need for supplementary oxygen & 14 (87.5\%) & II (68.75\%) & 0.39 \\
\hline \multicolumn{4}{|l|}{2 hours postoperatively } \\
\hline Need for supplementary oxygen & $4(25 \%)$ & $2(12.5 \%)$ & 0.65 \\
\hline \multicolumn{4}{|l|}{6 hours postoperatively } \\
\hline RASS lower than 0 at 2 hours & $10(62.5 \%)$ & $5(31.25)$ & 0.16 \\
\hline RASS lower than 0 at 6 hours & $2(12.5 \%)$ & $2(12.5 \%)$ & I \\
\hline
\end{tabular}

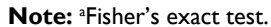

Abbreviation: RASS, Richmond Sedation and Agitation Scale.

mechanism of action by acting as an MOR agonist; meanwhile methadone is MOR agonist but also antagonizes glutamate by blocking the NMDAr and inhibits reuptake of serotonin and noradrenaline. ${ }^{12}$ These other effects in pain transmission can enhance the analgesic potential of methadone when used in anesthesia compared with fentanyl. Probably the higher postoperative morphine consumption in the group has led to the higher incidence of PONV observed.

This is the first study to establish an evaluation for postoperative chronic pain in this population (pain for a period of longer than 2 months) $)^{27}$ and pain 3 months after surgery. No statistical differences at the spontaneous pain and dysesthesia symptoms occurred between the two groups, but patients of group M presented lower evoked pain scores after the mechanical stimulus. There is consistent evidence that a better postoperative analgesia is related to less chronic pain after surgery. ${ }^{28}$ The most important limitation for these results is that the sample size was not calculated for chronic postoperative pain. So, more data on chronic pain after surgery 
with different interventions are necessary to understand the long-term impact of different multimodal analgesia methods. Despite the evidence that better postoperative analgesia is related to less chronic pain after surgery, no other methadonerelated trial has yet conducted a long-term patient evaluation.

Many practitioners would choose to avoid methadone for the target population of this study favoring short-acting opioids or no opioids because of the long and variable halflife of methadone in a population prone to sleep apnea and airway obstruction. The results suggested otherwise, that the use of methadone as sole opioid in bariatric surgery for morbidly obese patients was safe and significantly reduced the postoperative opioid consumption, leading to lower pain scores at rest and at movement, less opioid-related nausea and vomiting, and better patient satisfaction.

\section{Disclosure}

The authors report no conflicts of interest in this work.

\section{References}

1. Gerbershagen HJ, Aduckathil S, van Wijck AJ, et al. Pain intensity on the first day after surgery: a prospective cohort study comparing 179 surgical procedures. Anesthesiology. 2013;118(4):934-944.

2. Beattie WS, Badner NH, Choi PT. Meta-analysis demonstrates statistically significant reduction in postoperative myocardial infarction with the use of thoracic epidural analgesia. Anesth Analg. 2003;97(3):919-920.

3. Pöpping DM, Elia N, Marret E, Remy C, Tramèr MR. Protective effects of epidural analgesia on pulmonary complications after abdominal and thoracic surgery: a meta-analysis. Arch Surg. 2008;143(10):990-999, discussion 1000

4. Singh N, Sidawy AN, Dezee K, et al. The effects of the type of anesthesia on outcomes of lower extremity infrainguinal bypass. $J$ Vasc Surg. 2006;44(5):964-970.

5. Kehlet H, Jensen TS, Woolf CJ. Persistent postsurgical pain: risk factors and prevention. Lancet. 2006;367(9522):1618-1625.

6. Rodgers A, Walker N, Schug S, et al. Reduction of postoperative mortality and morbidity with epidural or spinal anaesthesia: results from overview of randomised trials. BMJ. 2000;321(7275):1493.

7. Wu R, Haggar F, Porte N, et al. Assessing the feasibility of a randomised, double-blinded, placebo-controlled trial to investigate the role of intraperitoneal ropivacaine in gastric bypass surgery: a protocol. BMJOpen. 2014;4(8):e005823.

8. Agarwal R, Hecht TE, Lazo MC, Umscheid CA. Venous thromboembolism prophylaxis for patients undergoing bariatric surgery: a systematic review. Surg Obes Relat Dis. 2010;6(2):213-220.

9. Fernandez AZ, Demaria EJ, Tichansky DS, et al. Multivariate analysis of risk factors for death following gastric bypass for treatment of morbid obesity. Ann Surg. 2004;239(5):698-703.

Journal of Pain Research

\section{Publish your work in this journal}

The Journal of Pain Research is an international, peer reviewed, open access, online journal that welcomes laboratory and clinical findings in the fields of pain research and the prevention and management of pain. Original research, reviews, symposium reports, hypothesis formation and commentaries are all considered for publication.
10. Shaiova L, Berger A, Blinderman CD, et al. Consensus guideline on parenteral methadone use in pain and palliative care. Palliat Support Care. 2008;6(2):165-176.

11. Toombs JD, Kral LA. Methadone treatment for pain states. Am Fam Physician. 2005;71(7):1353-1358.

12. Kharasch ED. Intraoperative methadone: rediscovery, reappraisal, and reinvigoration? Anesth Analg. 2011;112(1):13-16.

13. Murphy GS, Szokol JW, Avram MJ, et al. Intraoperative methadone for the prevention of postoperative pain. Anesthesiology. 2015;122(5): $1112-1122$.

14. Udelsmann A, Maciel FG, Servian DC, et al. Methadone and morphine during anesthesia induction for cardiac surgery. Repercussion in postoperative analgesia and prevalence of nausea and vomiting. Rev Bras Anestesiol. 2011;61(6):695-701.

15. Gottschalk A, Durieux ME, Nemergut EC. Intraoperative methadone improves postoperative pain control in patients undergoing complex spine surgery. Anesth Analg. 2011;112(1):218-223.

16. Simoni RF, Cangiani LM, Pereira AM, et al. Efficacy of intraoperative methadone and clonidine in pain control in the immediate postoperative period after the use of remifentanil. Rev Bras Anestesiol. 2009;59(4):421-430.

17. Chui PT, Gin T. A double-blind randomised trial comparing postoperative analgesia after perioperative loading doses of methadone or morphine. Anaesth Intensive Care. 1992;20(1):46-51.

18. Richlin DM, Reuben SS. Postoperative pain control with methadone following lower abdominal surgery. J Clin Anesth. 1991;3(2): 112-116.

19. Gourlay GK, Willis RJ, Lamberty J. A double-blind comparison of the efficacy of methadone and morphine in postoperative pain control. Anesthesiology. 1986;64(3):322-327.

20. Berde CB, Beyer JE, Bournaki MC, Levin CR, Sethna NF. Comparison of morphine and methadone for prevention of postoperative pain in 3- to 7-year-old children. J Pediatr. 1991;119(1 Pt 1):136-141.

21. Mercadante S, Villari P, Ferrera P, Casuccio A, Gambaro V. Opioid plasma concentrations during a switch from transdermal fentanyl to methadone. J Palliat Med. 2007;10(2):338-344.

22. Mercadante S, Ferrera P, Villari P, et al. Frequency, indications, outcomes, and predictive factors of opioid switching in an acute palliative care unit. J Pain Symptom Manage. 2009;37(4):632-641.

23. Mercadante $\mathrm{S}$, Bruera $\mathrm{E}$. The effect of age on opioid switching to methadone: a systematic review. J Palliat Med. 2012;15(3):347-351.

24. Robinson JD, Lupkiewicz SM, Palenik L, Lopez LM, Ariet M. Determination of ideal body weight for drug dosage calculations. Am J Hosp Pharm. 1983;40(6):1016-1019.

25. Shah B, Sucher K, Hollenbeck CB. Comparison of ideal body weight equations and published height-weight tables with body mass index tables for healthy adults in the United States. Nutr Clin Pract. 2006;21(3):312-319.

26. Lötsch J. Pharmacokinetic-pharmacodynamic modeling of opioids. J Pain Symptom Manage. 2005;29(5 Suppl):90-103.

27. Macrae WA, Davies HTO. Chronic postsurgical pain. In: Crombie IK, editor. Epidemiology of Pain. Seattle: IASP Press; 1999:125-142.

28. de Brito Cançado TO, Omais M, Ashmawi HA, Torres ML. Chronic pain after cesarean section. Influence of anesthetic/surgical technique and postoperative analgesia. Rev Bras Anestesiol. 2012;62(6): $762-774$.

\section{Dovepress}

The manuscript management system is completely online and includes a very quick and fair peer-review system, which is all easy to use. Visit http://www.dovepress.com/testimonials.php to read real quotes from published authors. 